\title{
The Environmental Impact Reduction obtained by implementing an Energy Management System. The advantages of using Energy Management and Energy Savings Standards when performing Industrial Energy Audits
}

\author{
Mircea Scripcariu ${ }^{1}$, Ioan Sevastian Bitir-Istrate ${ }^{2}$, Cristian Gheorghiu ${ }^{3 *}$ and Aida Maria \\ $\mathrm{Neniu}^{4}$ \\ ${ }^{1}$ Associate Prof., Dept. of Energy Production and Use, University POLITEHNICA of Bucharest, \\ Romania \\ ${ }^{2}$ Associate Prof., Dept. of Energy Production and Use, University POLITEHNICA of Bucharest, \\ Romania \\ ${ }^{3} \mathrm{PhD}$. Student, Dept. of Energy Production and Use, University POLITEHNICA of Bucharest, \\ Romania \\ ${ }^{4} \mathrm{PhD}$. Student, Dept. of Energy Production and Use, University POLITEHNICA of Bucharest, \\ Romania
}

\begin{abstract}
Energy audits are used world-wide for developing energy efficiency projects. Industrial consumers have complex energy supply, generation and distribution networks and a variety of energy use installations. Romanian industrial companies became more interested in the last years in implementing Energy Management Systems in accordance with ISO 50001 standard. This paper presents a comparison of using the current way of developing energy audits and the concepts provided by the ISO group of standards, by quantifying the environmental impact reduction generated by each methodology. Authors pointed out that current legislation does not fully match the rigors of the ISO 50001 group of standards when evaluating the Energy Baseline (EB), the Energy Performance Indicators (EPI) or the Energy Performance Improvement Actions (EPIA), thus leading to a lower global energy efficiency improvement in the hypothesis of implementing all the recommended EPIAs [1]. Identifying and developing energy efficiency measures following the recommendations of the energy management and energy savings group of standards may be more consistent and less risky for the industrial company, which in turn can lead to an overall improvement of the Carbon Footprint [2].
\end{abstract}

\section{Introduction}

\footnotetext{
* Corresponding author: gheorghiu.cristian.k@gmail.com
} 
The improvement of energy efficiency is a strategic objective of the national energy policy [3]. The main deficiency of the energy performance improvement program that every industrial end-user that records an equivalent energy consumption of over 1.000 t.o.e. (tons of oil equivalent) has to submit to A.N.R.E. (Romanian Energy Regulatory Agency) consists of [4]: a poor correlation between the declared plan and the actual and the predicted energy consumption, including irrelevant actions, with respect to the total energy consumption and the type of energy that has the biggest share and the lack of relevant benchmarking data and the poorly reported energy management data.

Even though the regulatory authority constantly tries to improve the Energy Audit Guide that provides rules that every auditing licensed entity must follow, the lack of metering energy inputs/outputs, the impossibility to correlate energy flows with the final product and the lack of an energy performance financial support scheme that can benefit from the aforementioned energy performance improvement, leads to an unsystematic implementation of the identified EPIAs.

In this paper the potential of improving the quality of an Industrial Energy Audit by implementing an EnMS (Energy Management System) in accordance to the ISO 50001 group of standards was analysed. The main issues that derived from the general requirements of the ISO 50001 group of standards were the normalization of the EPIs, respectively the EnB.

\section{Classic Energy Audit vs. ISO 50001 based Energy Audit}

In order to point out the benefits derived from implementing an EnMS in accordance to the ISO 50001 group of standards, the differences between the two methodologies were compared.

For the case study the latest Energy Audit [5] that the industrial end-user reported towards A.N.R.E., for the reference period 2015 - 2017. The share of each energy form that make up the total energy consumption shown in Fig.1, based on the aforementioned Energy Audit. The share of each energy form was considered equal to the reference period monthly average.

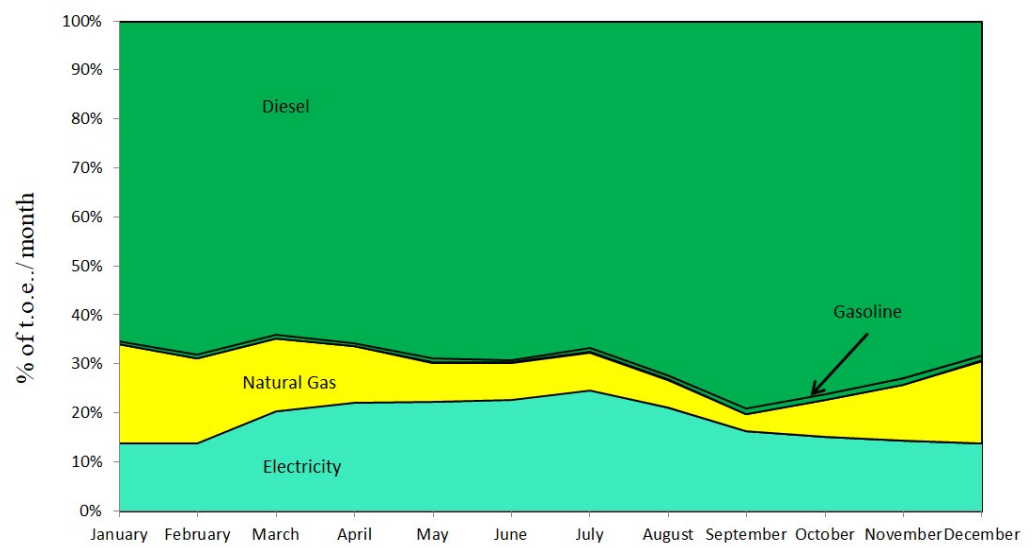

Fig. 1. The share of each energy form in the total, multiannual average energy consumption

As it can be easily seen in Fig. 1, Diesel holds the most significant share in the total energy consumption, averaging at about $72 \%$ of the total equivalent energy consumption. We will further propose and analyse the technical and the economic effect of an EPIA directed towards Diesel consumption. 
Firstly, the reference period for the Diesel consumption - EPI (as seen in Table 1), respectively the $\boldsymbol{E} \boldsymbol{n} \boldsymbol{B}$ for the average monthly fuel consumption (as seen in Fig. 2) were determined, considering a conversion factor of 1.015 t.o.e./ton of Diesel [6]. The reference period for the case-study is 2015-2017 and the reporting period is 2018-2027.

Table 1. Reference period Diesel consumption, in tons and in t.o.e.

\begin{tabular}{|c|c|c|c|c|c|c|c|c|c|c|c|c|c|c|}
\hline YEAR & M.U & Jan & $\mathrm{Feb}$ & Mar & Apr & May & Jun & Jul & Aug & Sept & Oct & Nov & Dec & TOTAL \\
\hline 2015 & \multirow{3}{*}{ tons } & 0.60 & 0.28 & 1.11 & 0.44 & 1.41 & 1.31 & 1.81 & 0.47 & 0.86 & 0.57 & 0.34 & 0.77 & 9.97 \\
\hline 2016 & & 0.22 & 1.87 & 1.36 & 1.48 & 2.59 & 0.86 & 3.49 & 2.03 & 2.34 & 1.92 & 2.92 & 1.10 & 22.18 \\
\hline 2017 & & 1.40 & 1.04 & 1.56 & 1.82 & 2.76 & 1.96 & 2.07 & 2.92 & 1.80 & 1.62 & 0.75 & 0.86 & 20.56 \\
\hline YEAR & M.U & Jan & Feb & Mar & Apr & May & Jun & Jul & Aug & Sept & Oct & Nov & Dec & TOTAL \\
\hline 2015 & \multirow{3}{*}{ t.o.e } & 0.63 & 0.29 & 1.17 & 0.46 & 1.48 & 1.38 & 1.90 & 0.49 & 0.90 & 0.60 & 0.36 & 0.81 & 10.47 \\
\hline 2016 & & 0.23 & 1.96 & 1.43 & 1.55 & 2.72 & 0.90 & 3.66 & 2.13 & 2.46 & 2.02 & 3.07 & 1.16 & 23.29 \\
\hline 2017 & & 1.47 & 1.09 & 1.64 & 1.91 & 2.90 & 2.06 & 2.17 & 3.07 & 1.89 & 1.70 & 0.79 & 0.90 & 21.59 \\
\hline
\end{tabular}

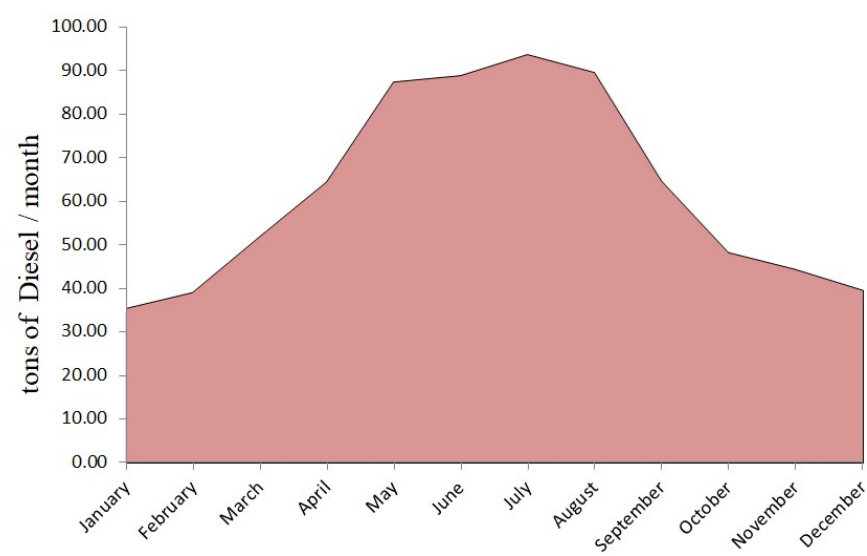

Fig. 2. The un-normalized EnB for the Diesel Consumption - EPI during the reference period (20152017)

The next step is proposing an appropriate $\boldsymbol{E P I A}$ to be evaluated in the two aforementioned scenarios - a Classic Energy Audit versus an ISO 50001 group of standards based Energy Audit. While keeping in mind that the Diesel consumption is generated by the cars fleet, which has the structure detailed in Table 2, the impact of replacing 44 of the 87 existing vans ( 3.5 to 7 ton) with 88 lighter, more efficient, 3.5 ton utility vehicles with an average consumption of $91 / 100 \mathrm{~km}$ was analysed. This $\boldsymbol{E P I A}$ is also supported by the seasonality of the ice-cream production, presented in Fig. 3, which can be correlated to an inefficient use of the carrying capacity of the actual cars fleet. 
Table 2. The structure of the analysed industrial consumer utility vehicle fleet

\begin{tabular}{|c|c|c|c|}
\hline Utility Vehicle Type & $\begin{array}{c}\text { Quantity } \\
{[\text { Pcs.] }}\end{array}$ & Fuel Type & $\begin{array}{c}\text { Average Fuel Consumption } \\
{[\mathbf{l} / \mathbf{1 0 0} \mathbf{~ k m}]}\end{array}$ \\
\hline Utility vehicle - under 3 tons & 33 & Diesel & 8 \\
\hline Refrigerated van - under 3.5 tons & 95 & Diesel & 12 \\
\hline Refrigerated truck $-3.5-7$ tons & 87 & Diesel & 20 \\
\hline Refrigerated truck $-7-12$ tons & 1 & Diesel & 35 \\
\hline Utility Truck Head & 1 & Diesel & $3.51 / \mathrm{h}$ \\
\hline Semitrailer & 1 & Diesel & 8 \\
\hline Special shop utility vehicle & 2 & Diesel & - \\
\hline Semi tanker & 1 & - & \\
\hline
\end{tabular}

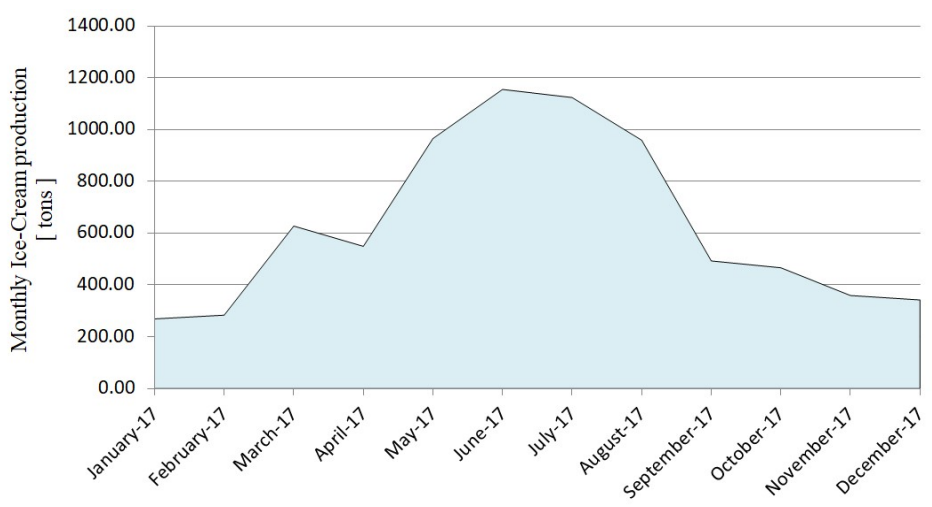

Fig. 3. The monthly production in 2017

For the technical and economic analysis, a series of hypothesis regarding the technical characteristics of the proposed replacement-vehicle, supported by an offer submitted by a utility vehicles producer were made, see Table 3.

Table 3. The technical characteristics of the proposed vehicles

\begin{tabular}{|c|c|c|}
\hline Characteristic & Value & M.U. \\
\hline Engine Displacement & 2.998 & {$[\mathrm{~cm} 3]$} \\
\hline Engine Power & 156 & {$[\mathrm{BHP}]$} \\
\hline Fuel Type & Diesel & {$[-]$} \\
\hline Average Fuel Consumption & 9 & {$[1 / 100 \mathrm{~km}]$} \\
\hline EU Emission Standard & Euro 6 & {$[-]$} \\
\hline Maximum Weight & 3.5 & {$[$ tons] } \\
\hline Refrigerator Box Temperature & $0-2$ & {$\left[{ }^{\circ} \mathrm{C}\right]$} \\
\hline Normal Use Time[7] & 6 & {$[$ years] } \\
\hline Producer Warranty & 2 & {$[$ years] } \\
\hline
\end{tabular}

Furthermore, for the economic analysis of the proposed $\boldsymbol{E P I A}$ the following input data was considered: 
$>$ The number of refrigerated trucks replaced each year: 4 pcs;

$>$ The number of refrigerated vans bought each year: 8 pcs;

$>$ The price of a refrigerated van: 24,000 EUR, without VAT;

$>$ The price of a re-sold refrigerated truck: 10,000 EURO, without VAT;

$>$ The yearly maintenance cost per van while in the warranty period: 300 EUR/van;

$>$ The yearly maintenance cost per van while out of the warranty period: 500 EUR/van;

$>$ The discount rate: $\mathrm{r}=9 \% /$ annum $[8]$;

$>$ The analysis period:2017-2027 - based on the fact that the investment in the EPIA began in August, 2017;

$>$ The reporting period: $2018-2027$ - this period is used to quantify and monetize the energy savings generated by the implementation of the $\boldsymbol{E P I A}$.

The 10 years reporting period will generate a number of risks such as: Diesel price evolution legislation, social and political, climate etc. and the high value of the investment in the proposed EPIA makes it necessary to split this payment over a longer period of time in order to maintain a reasonable degree of economic efficiency and be accepted by decision-makers.

\subsection{Classic Energy Audit approach}

In the Classic Energy Audit case, due to the industrial consumer inability to forecast the $\boldsymbol{E P I}$ 's evolution, a hypothesis is made: the production and Diesel consumption are similar to the las year of the reference period for entire analysis period. Using the NPV (Net Present Value) criterion by applying the $1^{\text {st }}$ formula, respectively the IRR (Internal Rate of Return) [9], and the C/B (Cost Benefit Analysis) described in equations 2 and 3, for a generally accepted interest rate $\mathrm{r}=9 \% /$ annum, the EPIA appears to be unattractive. The results are summarized in Table 4.

$$
N P V=I_{\text {annual }} \cdot T_{\text {tst }}-I-O \& M \cdot T_{\text {tst }}[€]
$$

where $\mathrm{I}_{\text {annual }}=$ annual economy generated by the $E P I A, \mathrm{~T}_{\text {tst }}=$ discount factor, $\mathrm{I}=$ initial investment in the $E P I A, \mathrm{O} \& \mathrm{M}=$ operating and maintenance costs.

$$
I R R=r_{a}+\frac{N V P_{a}}{N V P_{a}-N V P_{b}} \cdot\left(r_{b}-r_{a}\right)[\%]
$$

where $r_{a}=$ lower discount rate, $r_{b}=$ higher discount rate, NPV $a=$ the NPV for $r_{a}, N V_{b}$ $=$ the NPV for $r_{b}$.

$$
B / C=\frac{\text { undiscounted annual benefit }}{\text { initial investment cost }}[-]
$$

Table 4. The results of the technical-economic analysis - classic Energy Audit approach

\begin{tabular}{|c|c|c|}
\hline Unit & Value & M.U. \\
\hline NPV & $-383,789$ & {$[$ EUR] } \\
\hline IRR & - & {$[\% /$ year $]$} \\
\hline
\end{tabular}




\begin{tabular}{|c|c|c|}
\hline $\mathrm{B} / \mathrm{C}$ & -2 & {$[-]$} \\
\hline Carbon Footprint Reduction & $4,736.74$ & {$\left[\right.$ tons $\mathrm{CO}_{2} /$ year $]$} \\
\hline
\end{tabular}

The total Carbon Footprint reduction generated by the analysed EPIA in this scenario totalled a mere 4,736.74 tonnes of $\mathrm{CO}_{2}$ for the entire reporting period for a conversion factor of 3.183 grams of $\mathrm{CO}_{2} / \mathrm{kg}$ of Diesel [10].

In Fig. 4, the predicted Diesel consumption as a result of implementing the analysed EPIA can be noticed to have an almost linear variation, due to the fact that neither the predicted production, nor the predicted Diesel consumption, were normalized.

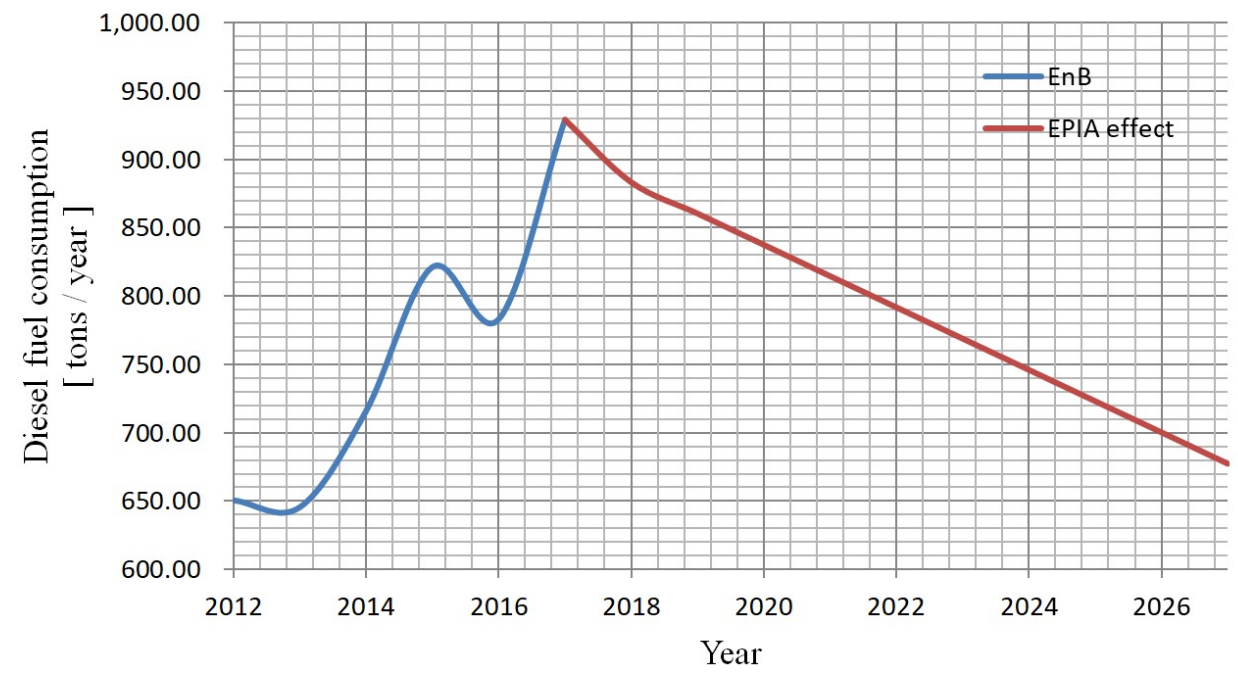

Fig. 4. The EPIA effect to the non-normalized Diesel Consumption

\subsection{ISO 50001 standard based Energy Audit approach [11]}

Because the linear regression method for normalizing the analysed EPIs lead, in some cases, to an unacceptable standard deviation, greater than $45 \%$, we used Python's scipy.interpolate.InterpolatedUnivariateSpline algorithm to determine the normalization function for both the main EPI - Diesel Consumption and the variable factors - Average outdoor temperature and average monthly food and non-alcoholic beverages expenditures per family - that are influencing it. In order to do so, a list of static and variable factors, presented in Table 5, was firstly set up.

Table 5. Static and variable factors [11-12] used for the normalization of the analysed EPI

\begin{tabular}{|c|c|c|c|c|c|}
\hline \multirow{2}{*}{ FACTOR } & \multirow{2}{*}{ TYPE } & \multicolumn{3}{|c|}{ REFERENCE PERIOD } & \multirow{2}{*}{ M.U. } \\
\hline & & 2015 & 2016 & 2017 & \\
\hline No. of production lines & Static & 2 & 2 & 2 & [pcs. ] \\
\hline Work shifts no. & Static & 1 & 1 & 1 & shifts/day ] \\
\hline Average no. of employees & Static & 542 & 586 & 623 & [pcs. ] \\
\hline $\begin{array}{l}\text { No. of deposits outside the audited energy } \\
\text { boundary }\end{array}$ & Static & 1 & 1 & 1 & [pcs. ] \\
\hline Average outdoor temperature & Variable & & ee table & & {$\left[{ }^{\circ} \mathrm{C}\right]$} \\
\hline $\begin{array}{l}\text { Average monthly food and non-alcoholic } \\
\text { beverages expenditures per family }\end{array}$ & Variable & 665.16 & 653.22 & 699.67 & [ RON/family ] \\
\hline
\end{tabular}

Table 6. Average outdoor temperature in the geographic area of the audited energy boundary 


\begin{tabular}{|c|c|c|c|c|}
\hline Month & $\mathbf{2 0 1 5}$ & $\mathbf{2 0 1 6}$ & $\mathbf{2 0 1 7}$ & M.U. \\
\hline January & 2 & 0 & -3 & {$\left[{ }^{\circ} \mathrm{C}\right]$} \\
\hline February & 4 & 9 & 3 & {$\left[{ }^{\circ} \mathrm{C}\right]$} \\
\hline March & 9 & 11 & 13 & {$\left[{ }^{\circ} \mathrm{C}\right]$} \\
\hline April & 16 & 20 & 15 & {$\left[{ }^{\circ} \mathrm{C}\right]$} \\
\hline May & 24 & 21 & 22 & {$\left[{ }^{\circ} \mathrm{C}\right]$} \\
\hline June & 27 & 29 & 28 & {$\left[{ }^{\circ} \mathrm{C}\right]$} \\
\hline July & 32 & 31 & 29 & {$\left[{ }^{\circ} \mathrm{C}\right]$} \\
\hline August & 31 & 30 & 31 & {$\left[{ }^{\circ} \mathrm{C}\right]$} \\
\hline September & 26 & 25 & 23 & {$\left[{ }^{\circ} \mathrm{C}\right]$} \\
\hline October & 15 & 13 & 15 & {$\left[{ }^{\circ} \mathrm{C}\right]$} \\
\hline November & 12 & 7 & 9 & {$\left[{ }^{\circ} \mathrm{C}\right]$} \\
\hline December & 7 & 2 & 6 & {$\left[{ }^{\circ} \mathrm{C}\right]$} \\
\hline
\end{tabular}

In order to properly forecast the predicted energy savings generated from implementing the analysed EPIA, a set of predicted values for the key variable factors have been considered - see Fig. 5 and Table 7.

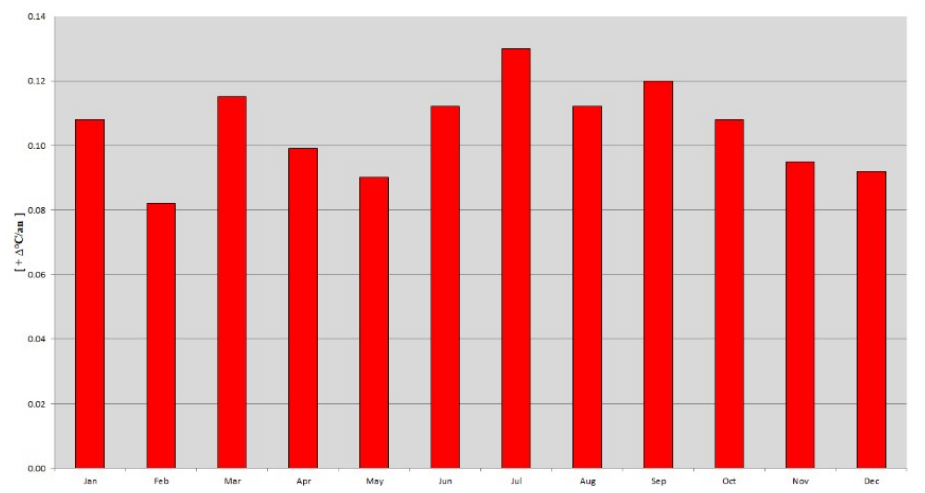

Fig. 5. The average temperature variation for the reporting period [13]

Table 7. The forecast of the average monthly food and non-alcoholic expenditures per family

\begin{tabular}{|c|c|c|c|c|c|c|}
\hline Indicator & M.U. & 2020 & 2025 & 2030 & 2035 & 2042 \\
\hline $\begin{array}{c}\text { Average monthly } \\
\text { food and non- } \\
\text { alcoholic beverages } \\
\text { expenditures per } \\
\text { family }\end{array}$ & {$[\mathrm{RON} /$ month] } & 711.45 & 823.91 & $1,134.6$ & $1,567.65$ & $2,256.13$ \\
\hline
\end{tabular}

Based on the second set of variable factors, the normalization function for the production during reporting period is presented in Fig. 6.

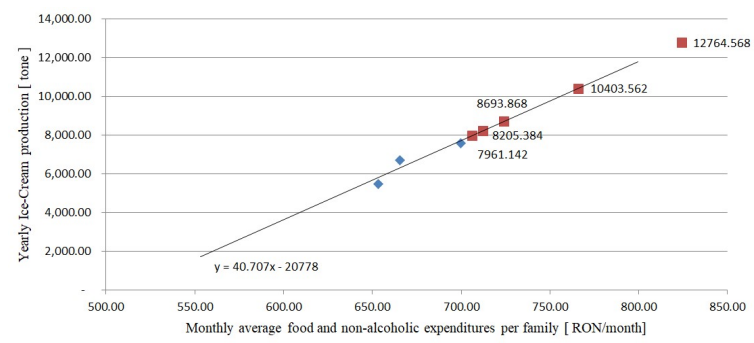

Fig. 6. The normalization of the predicted yearly Production with respect to the predicted increase of the monthly average food and non-alcoholic expenditures per family - linear regression

For determining the variation function of the production with respect to the monthly average exterior temperature (Production $=\mathrm{f}$ (temperature) ant the monthly average food 
and non-alcoholic expenditures per family (Production $=\mathrm{f}$ (expenditures)), the linear regression method was used. The determined linear functions were overlapped and the intersection of them was considered the normalized function of Production $=\mathrm{f}$ (temperature, expenditures).

By applying the double-normalized predicted yearly production to the aforementioned Python function, which fits a spline $\mathrm{y}=\operatorname{spl}(\mathrm{x})$ of degree $\mathrm{k}$ to the provided $\mathrm{x}, \mathrm{y}$ data via a Lagrange interpolation technique (4), the predicted Diesel consumption, during the reporting period was obtained.

$$
P(x)=\sum_{j=1}^{n} P_{j}(x)=\sum_{j=1}^{n} \delta_{j k} \cdot y_{k}=y_{j}
$$

where $\mathrm{x}=$ double normalized predicted yearly production, $\mathrm{y}=$ predicted Diesel consumption and $\delta=$ the $k$ degree constant.

By applying the Lagrange interpolation technique, the normalized Diesel consumption $\mathrm{P}(\mathrm{x})$ - was determined as being a $36^{\text {th }}$ degree polynomial function.

The predicted production is limited to 10,000 tons/ year due to the no. of production lines, considered to be a static factor (see Table 5). Based on this newly obtained predicted Diesel consumption, the NPV / IRR/ B/C indicators were re-evaluated. The results are presented in Table 8.

Table 8. The results of the technical-economic analysis - ISO 50001 group of standards approach

\begin{tabular}{|c|c|c|}
\hline Unit & Value & M.U. \\
\hline NPV & 9,070 & {$[$ EUR] } \\
\hline IRR & 10 & {$[\% /$ year $]$} \\
\hline B/C & 0.05 & {$[-]$} \\
\hline Carbon Footprint Reduction & $7,200.22$ & {$\left[\right.$ tons $\mathrm{CO}_{2} /$ year $]$} \\
\hline
\end{tabular}

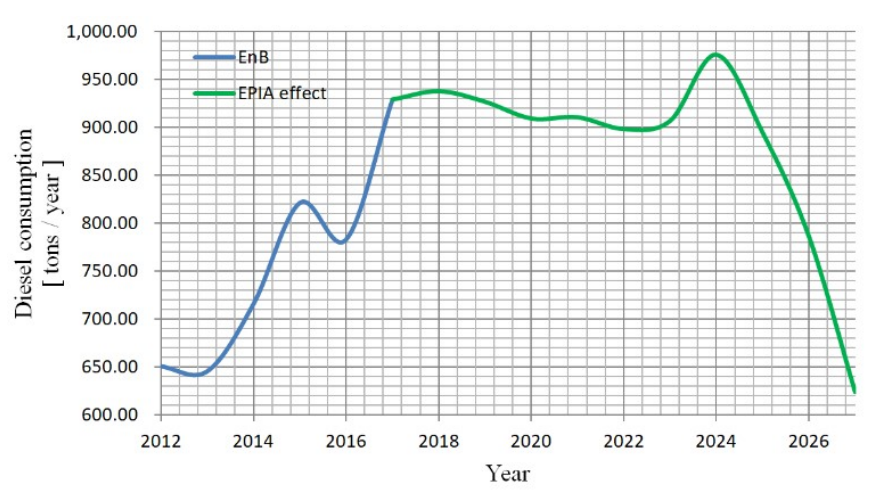

Fig. 7. The EPIA effect on the double-normalized Diesel consumptions, using ISO 50001 approach

The total carbon footprint generated by the analysed $\boldsymbol{E P I A}$ in this scenario totalled 7,300.22 tonnes of $\mathrm{CO}_{2}$ for the entire reporting period.

In Fig. 7, the predicted Diesel consumption as a result of implementing the analysed $\boldsymbol{E P I A}$ can be seen to have a non-linear variation, due to the fact that both the predicted production and the predicted Diesel consumption were normalized. The Diesel consumption begins to have a linear variation starting from 2024 until the end of the 
reporting period, in 2027, because of the technological limitation that prohibits the production variable to further increase above the 10,000 tons/year threshold.

\section{Conclusions}

Normalizing the production with the average daily outdoor temperature and the monthly average expenditures per family on food and non-alcoholic beverages helps the decisionmaking for energy efficiency projects, both variable factors having an obvious influence on the quantity of items produced, distributed, sold and consumed.

By using the normalized production to analyse the main EPI - Diesel fuel consumption, the results of the NPV method were drastically affected in a positive manner. This can also be observed in Fig. 8, which depicts the predicted Diesel consumption during the reporting period in both analysed cases.

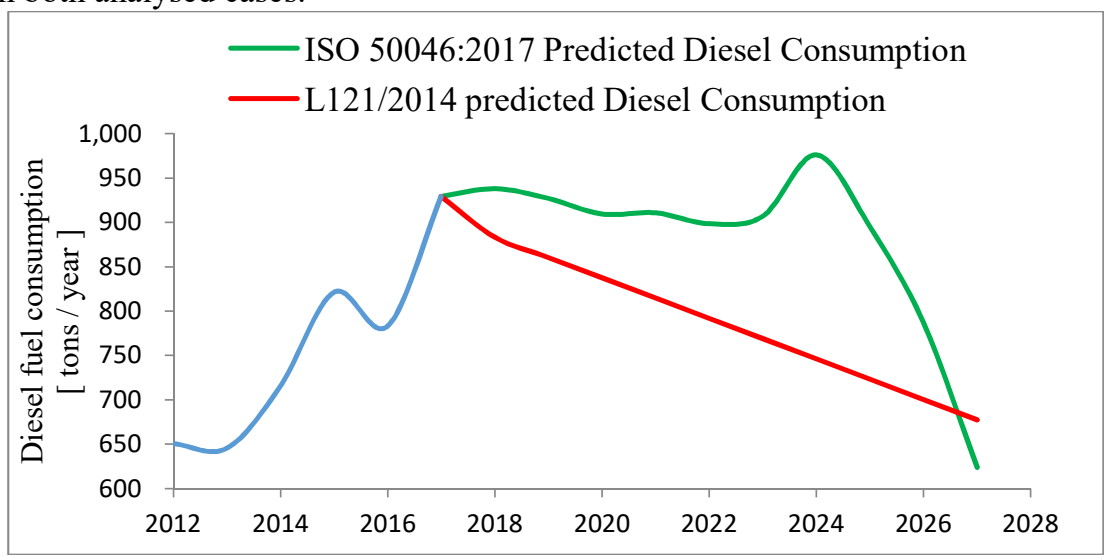

Fig. 8. The EPIA effect on Diesel consumptions during the reporting period without taking the static and variable factors into account (red), respectively with respect to the static and variable factors (green)

The main issues that authors encountered while applying the ISO 50001 standard proposed methodology were the inability to determine all the relevant variable factors, and the difficulty of determining the relevant variable factors values both from measurements and from official forecasts.

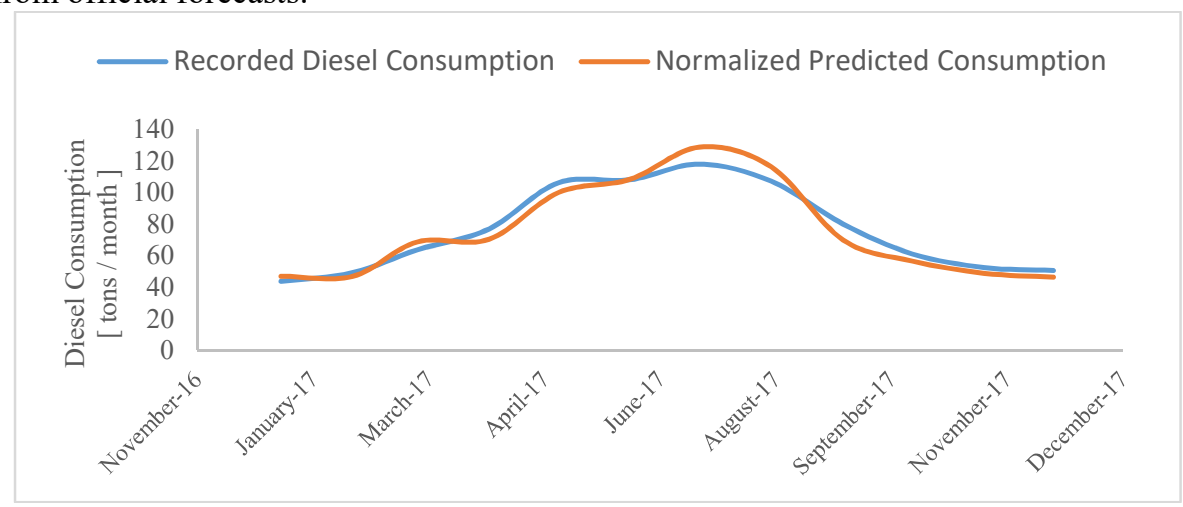

Fig. 9. The EPI - Diesel Consumption in 2017, based on its recorded values (blue) and the forecast, normalized values (red), based on the $2012-2015$ production and outdoor temperature 
As it can be observed in Fig. 9, the algorithm used to evaluate the effect to the EPIA leads in this particular case to an under $10 \%$ standard deviation, that lead to the conclusion that using a higher rank for the interpolating function when developing an EPI normalizing method is worth further researching. The opportunity of developing a specific methodology for evaluating the energy efficiency of each industry type is obvious, as it is clear that both the static factors and the variable ones are also specific to each type of consumer/industry.

Furthermore, it is strongly recommended that a better method of normalizing the different types of EPIs should be developed. The development of a Neural Network that can analyse all the data that an advanced monitoring and metering system can feed in and determine a daily / monthly / yearly set of normalization functions for the analysed EPIs could further improve the benefit of using the ISO 50001 standard group methodology both for implementing a proper and efficient EnMS and for the periodic Energy Auditing process.

\section{References}

1. I. Dzene, I. Polikarpova, L. Zogla, and M. Rosa, Application of ISO 50001 for Implementation of Sustainable Energy Action Plans, ENERGY PROCEDIA, 72, pp. 111-118 (2015)

2. F. Marimon and M. Casadesus, Reason to adopt ISO 50001 Energy Management System, SUSTAINABILITY, 9 (2017)

3. The Romanian Parliament, Energy efficiency Law no 121/2014 (04.08.2014)

4. A.N.R.E., Decision 8/DEE/12.05.2015 - Energy Efficiency Improvement Program Model for industrial consumers (2015)

5. S.C. ELSACO ESCO S.R.L., Complex Energy Audit of the analysed industrial consumer (2016)

6. $* * *$, https://ec.europa.eu/eurostat/statisticsexplained/index.php/Glossary:Tonnes_of_oil_equivalent_toe)

7. The Romanian Government, Government Decision no. 2139/2004 - Classification and Normal Use Time of fixed assets (2004)

8. Public Procurement National Agency, Order no. 2717/318/2018 for the revision of the discount rate (2019)

9. Y. K. Shestopaloff, A.Yu. Shestopaloff - Solving the Puzzle of IRR Equation. Choosing the Right Solution to Measure Investment Success, AKVY PRESS (2011)

10. ***, (2017), https://www.eia.gov/tools/faqs/faq.php?id=307\&t=11

11. International Standardisation Organization, ISO 50001:2018 Energy Management Systems - Requirements with quidance for use (2018)

12. International Standardisation Organization, ISO 50047:2016 Energy savings Determination of energy savings in Organizations (2016)

13. R. Bojariu, M.V. Bîrsan, R. Cică, L. Velea, S. Burcea, A. Dumitrescu, S. I. Dascălu, M. Gothard, A. Dobrinescu, F. Cărbunaru, and L. Marin, Climate Change - from the physics basics to risk and adaptation (in Romanian language), Printech publishing house (2015) 